\title{
Left Ventricular Geometrical Changes in Severely Obese Adolescents: Prevalence, Determinants, and Clinical Implications
}

\author{
Ali Talib ${ }^{1,2}$ - Yvonne G. M. Roebroek ${ }^{1,2,3} \cdot$ Givan F. Paulus $^{2,4} \cdot$ Kris van Loo $^{5} \cdot$ Bjorn Winkens $^{6} \cdot$ Nicole D. Bouvy $^{1,2}$. \\ Ernst L. W. E. van Heurn ${ }^{1,2,7}$
}

Received: 3 June 2020 / Accepted: 8 October 2020 / Published online: 20 October 2020

(c) The Author(s) 2020

\begin{abstract}
Left ventricular hypertrophy (LVH) is independently associated with a higher risk of cardiovascular morbidity and mortality in adults. Adiposity is a risk factor for $\mathrm{LVH}$, independent of blood pressure. Potential causes of this nonhemodynamic pathogenesis identified in adults include adverse body fat distribution, insulin resistance, dyslipidemia, and obstructive sleep apnea syndrome (OSA). In severely obese adolescents, the determinants of obesity-induced changes in left ventricular structure are poorly characterized. Cardiac ultrasonographic, demographic, anthropometric, and comorbidity-related data were prospectively collected in adolescents with severe obesity refractory to conservative treatment who presented for surgical therapy. Differences between adolescents with LVH and without LVH were evaluated using independent samples $t$, chi-square, or Fisher's exact test. Multivariable linear regression analysis was performed to evaluate associations with left ventricular structural changes, corrected for body mass index (BMI) $z$ score. Forty-three patients entered analysis, of whom $24(55.8 \%)$ showed LVH. The most common geometrical change was eccentric LVH (eLVH), occurring in 21 subjects (48.8\%). Demographic and anthropometric variables did not differ between patients with and without LVH. Independent of BMI $z$ score, left ventricular mass index was significantly associated with apnea-hypopnea index (AHI) (regression parameter $B=0.8$; $95 \%$ CI 0.3 to 1.2$)$. Interventricular septum thickness (IVST) was significantly associated with HOMA-IR values $(B=0.1$; 95\% CI 0.04 to 0.2$)$, HDL-cholesterol $(B=-1.2 ; 95 \% \mathrm{CI}-2.2$ to 0.1$)$, and triglyceride levels $(B=0.5 ; 95 \%$ CI 0.001 to $0.9)$. $\mathrm{LVH}$, especially eLVH, is highly prevalent amongst severely obese adolescents. Adverse changes in cardiac structure, increased IVST in particular, are independently associated with several nonhemodynamic comorbidities that are common in this population, namely OSA, insulin resistance, and dyslipidemia.
\end{abstract}

Keywords Left ventricular hypertrophy $\cdot$ Left ventricular geometry $\cdot$ Severe obesity $\cdot$ Adolescents

\section{Abbreviations}

AHI Apnea hypopnea index

BMI Body mass index

cLVH Concentric left ventricular hypertrophy

cLVR Concentric left ventricular remodeling

eLVH Eccentric left ventricular hypertrophy
DBP Diastolic blood pressure

HOMA-IR Homeostatic model assessment of insulin resistance

IVST Interventricular septal thickness

LVEDD Left ventricular end-diastolic dimension

LVESD Left ventricular end-systolic dimension
Ali Talib

ali.talib@mumc.nl

1 Department of Surgery, Maastricht University Medical Center, P. Debyelaan 25, 6229 HX Maastricht, The Netherlands

2 NUTRIM School for Nutrition and Translational Research in Metabolism, Maastricht University, Maastricht, The Netherlands

3 Department of General Surgery, Maxima Medical Center, Veldhoven, The Netherlands
4 Department of General Surgery, Spaarne Gasthuis, Haarlem, The Netherlands

5 Department of Pediatrics, Maastricht University Medical Center, Maastricht, The Netherlands

6 Department of Methodology and Statistics, CAPHRI Care and Public Health Research Institute, Maastricht University, Maastricht, The Netherlands

7 Department of Pediatric Surgery, Amsterdam University Medical Centers, Amsterdam, The Netherlands 


$\begin{array}{ll}\text { LVH } & \text { Left ventricular hypertrophy } \\ \text { LVM } & \text { Left ventricular mass } \\ \text { LVMI } & \text { Left ventricular mass index } \\ \text { LVPWT } & \text { Left ventricular posterior wall thickness } \\ \text { OSA } & \text { Obstructive sleep apnea syndrome } \\ \text { RWT } & \text { Relative wall thickness } \\ \text { SBP } & \text { Systolic blood pressure }\end{array}$

\section{Introduction}

Pediatric obesity is associated with adverse changes in left ventricular geometry, especially left ventricular hypertrophy (LVH) [1-6]. In adults, LVH increases the risk of ventricular arrhythmias and decompensation, and poses a fourfold increased risk of cardiovascular morbidity and mortality [7]. In hypertensive patients, the presence of LVH increases the risk of cardiovascular events by a factor 20 [8].

The reported prevalence of LVH in obese children, adolescents, and young adults between the ages of 3 and 22 years old ranges from 10 to $46 \%$ [1-6]. Although LVH is normally asymptomatic in children, multiple prospective longitudinal studies have established that several risk factors for adverse cardiovascular events persist into adulthood [9, 10]. Interestingly, on long-term follow-up of patients with essential hypertension, (partial) reversal of LVH by antihypertensive treatment has been found to reduce the risk of cardiovascular morbidity and mortality to the same level as those who did not have LVH at the beginning of follow-up [11]. This provides an argument for early detection of LVH in obese individuals and treatment of causative factors.

Adiposity is a predictor of LVH in both hypertensive and nonhypertensive children, independent of age [12-15]. The mechanisms underlying obesity-induced changes in left ventricular geometry are diverse and include hemodynamic factors (hypertension, increased intravascular volume), metabolic factors, hormonal factors, and factors related to OSA [16]. In the Bogalusa Heart study, it was found that young adults (aged 24-44 years) were more likely to suffer from LVH if they were exposed to risk factors of LVH in childhood, including obesity, diabetes, increased waist circumference, elevated systolic blood pressure (SBP) and diastolic blood pressure (DBP), insulin resistance, and dyslipidemia [17].

The aim of our research is to improve understanding of the prevalence and determinants of left ventricular geometrical changes in a homogeneous and well-characterized population of severely obese adolescents. We hypothesize that $\mathrm{LVH}$, especially eccentric $\mathrm{LVH}$, is highly prevalent in our population, that $\mathrm{BMI}$ is the most important anthropometric predictor of LVH, and that LVH is independently associated with several pathogenic factors, including blood pressure and variables related to insulin sensitivity, lipid profile, hormonal aberrancies, and OSA.

\section{Methods}

This study was conducted as part of a randomized controlled trial for adolescents eligible for bariatric surgery (BASIC trial, NCT01172899) [18]. The study population of the BASIC trial consists of severely obese adolescents who all have been treated extensively for their severe obesity by conservative methods during at least 12 months without effect. The current study was based on the baseline measurements of this trial, before randomization took place.

\section{Participants}

All patients included in the BASIC trial who received a baseline cardiac ultrasound examination were used for this baseline analysis. Detailed information regarding the BASIC trial study design, in- and exclusion criteria, and randomization process was published previously [18]. In summary, inclusion criteria were age 14-16 years; sex- and age-adjusted $\mathrm{BMI} \geq 40 \mathrm{~kg} / \mathrm{m}^{2}$ (or $\geq 35 \mathrm{~kg} / \mathrm{m}^{2}$ combined with presence of obesity-associated comorbidity); and participation in combined lifestyle interventions during at least 12 months without adequate weight loss (defined as $5 \%$ total body weight loss). In order to maintain a homogenous study population with regard to pubertal status, girls were excluded if they were premenarchal, boys if their bone age was $<15$ years.

All participants were subjected to standardized comprehensive baseline measurements and investigations in order to exclude (subclinical) conditions causing obesity.

\section{Measurements}

All measurements within one patient were carried out during a single visit. Body height and weight were measured using a stadiometer and digital scale, respectively, with patients dressed in underwear. A tape measure was used for standardized measurement of body circumferences at neck level, abdominal level, and hip level. BMI was calculated as [body weight]/[body height*body height] in $\mathrm{kg} / \mathrm{m}^{2}$, and BMI $z$ scores were calculated using Cole's LMS method [19]. Daytime blood pressure was measured while the patient was resting, during a period of 60 to $90 \mathrm{~min}$ with intervals of 3 min between measurements, using the Mobil-O-Graph ${ }^{\circledR}$ NG (I.E.M. GmbH, Stolberg, Germany). Prehypertension and hypertension were defined according to the fourth report from the National High Blood Pressure Education Program, and blood pressure $z$ scores were calculated according to the method described in that same report [20]. 
A fasting blood draw was performed to measure serum glucose, insulin, cholesterol, triglycerides, free fatty acids, glycated hemoglobin (HbA1C), and leptin. HOMAIR was calculated according to the method described by Mathews et al., i.e., ((fasting insulin (microU/l)/(fasting glucose $(\mathrm{mmol} / \mathrm{l})) / 22.5$, where insulin was converted from $\mathrm{pmol} / 1$ to microU/l by dividing by 6.945 [21].

Video-assisted 12 channel polysomnography (PSG) (Brain RT, OSG, Rumst, Belgium) was performed at the pediatrics department of Maastricht University Medical Center. The scoring of sleep stages and respiratoryrelated events were performed by a single specialized analyst using the American Academy of Sleep Medicine (AASM) 2012 updated guidance for scoring pediatric respiratory events [22].

All cardiac ultrasounds were planned with a single pediatric cardiologist, who reported interventricular septal thickness (IVST), left ventricular end-diastolic posterior wall thickness (LVPWT), left ventricular end-diastolic dimension (LVEDD), and left ventricular end-systolic dimension (LVESD). In the absence of this pediatric cardiologist, another experienced pediatric cardiologist was consulted to perform the ultrasound examination.

Left ventricular mass (LVM) was calculated using the Devereux formula, where left ventricular mass (in grams $)$ is equal to $0.8\left(1.04\left((\mathrm{LVEDD}+\mathrm{IVST}+\mathrm{LPWT})^{3}-\right.\right.$ $\left.\left.\mathrm{LVEDD}^{3}\right)\right)+0.6$ [23]. Left ventricular mass was subsequently indexed by dividing it by height to the power of 2.7, which was previously described as the optimal height exponent between children and adults for indexing LVM $[24,25]$. Thus, left ventricular mass index (LVMI) is equal to LVM divided by height ${ }^{2.7}$ (height in meters). $\mathrm{LVH}$ was defined as a LVMI $\geq 38.6 \mathrm{~g} / \mathrm{m}^{2.7}$, in accordance with the 95th percentile of LVM in a cohort of 192 healthy children of 6 to 17 years old [25].

Cardiac geometry was further specified using the relative wall thickness (RWT) and LVMI, according to the method of Ganau et al., where RWT was calculated as $2 *$ LVPWT/LVEDD [26]. In children, an RWT $>0.41$, corresponding to the 95th percentile of RWT in children and adolescents, corresponds to concentric changes, and an RWT $\leq 0.41$ corresponds to normal geometry or eccentric changes [27]. We defined normal geometry and concentric left ventricular remodeling (cLVR) as a normal LVMI $\left(<38.6 \mathrm{~g} / \mathrm{m}^{2.7}\right)$ with an RWT that is $\leq 0.41$ or $>0.41$, respectively. We defined left ventricular hypertrophy as a LVMI $\geq 38.6 \mathrm{~g} / \mathrm{m}^{2.7}$ and further specified this as eccentric left ventricular hypertrophy (eLVH) if RWT was $\leq 0.41$ and concentric left ventricular hypertrophy when RWT was $>0.41$.

\section{Statistical Analysis}

Numerical data are presented as mean \pm standard deviation and range where appropriate. Categorical data are presented as number (percentage). Demographic and clinical variables were compared between patients with no LVH and patients with $\mathrm{LVH}$, using an independent samples $t$ test for numerical variables and $\chi^{2}$ or Fisher's exact test for categorical variables. Multivariable linear regression analysis was used to evaluate the association between several relevant demographic, anthropometric, and comorbidity endpoints and LVMI, correcting for BMI $z$ score. As sensitivity analysis, these analyses were repeated, where we additionally corrected for age and gender. The associations between the dependent and independent variables were assessed separately as the sample size was too small to include all independent variables in one regression model. All assumptions were checked using plots (scatterplots for linearity, $Q-Q$ plots and histograms for normality, residual plots for homoscedasticity), where Cook's distance $>1$ was used to define an influential outlier. In case normality was violated, a log or square-root transformation was considered to achieve normality. IBM SPSS Statistics for Windows (version 24.0; Armonk, NY, USA) was used for the aforementioned statistical analyses. Two-sided $p$-value $\leq 0.05$ was considered statistically significant.

\section{Results}

Of the 60 adolescents included in the BASIC trial, 43 subjects received a baseline cardiac ultrasound, of whom 42 were performed by CvL. Seventeen patients did not receive an ultrasound due to logistic circumstances, mainly unavailability of a pediatric cardiologist.

The baseline characteristics of the 43 remaining adolescents are presented in Table 1 . The majority $(79.0 \%)$ was female; mean $( \pm \mathrm{SD})$ age was $15.7 \pm 1.0$ years; and BMI was on average $44.2 \pm 5.5 \mathrm{~kg} / \mathrm{m}^{2}$, with a mean BMI $z$ score of $3.5 \pm 0.3$.

The mean values measured with cardiac ultrasonography in our study population were: LVM of $170.4 \mathrm{~g}( \pm 42.3)$, LVMI of $40.4 \mathrm{~g} / \mathrm{m}^{2.7}( \pm 8.3)$, IVST of $9.6 \mathrm{~mm}( \pm 1.3)$, LVPWT of $9.1 \mathrm{~mm}( \pm 1.0)$, and LVEDD of $50.3 \mathrm{~mm}( \pm 4.7)$. The average RWT was $0.37( \pm 0.05)$. Twenty-four patients (55.8\%) had a LVMI of $\geq 38.6 \mathrm{~g} / \mathrm{m}^{2.7}$, corresponding to LVH according to the pediatric definition [25]. Figure 1 shows the geometrical distribution in our study population. eLVH, cLVH, and cLVR occurred in 21 (48.8\%), three (7.0\%), and two $(4.7 \%)$ patients, respectively.

Differences in demographic, anthropometric, and potentially pathogenic factors between patients with LVH and without LVH are shown in Tables 1 and 2 . We did not 
Table 1 Demographic and anthropometric characteristics for overall population and patients with LVH. * Fischer's exact test performed

\begin{tabular}{lllll}
\hline Variable & Overall $(n=43)$ & No LVH $(n=19)$ & LVH $(n=24)$ & $p$-value \\
\hline Demographic variables & & & & \\
$\quad$ Age (years) & $15.7( \pm 1.0)$ & $15.8( \pm 1.0)$ & $15.6( \pm 0.9)$ & 0.657 \\
Gender female $(\%)$ & $34(79.0 \%)$ & $17(89.4 \%)$ & $17(70.8 \%)$ & $0.257^{*}$ \\
Anthropometric variables & & & \\
BMI $\left(\mathrm{kg} / \mathrm{m}^{2}\right)$ & $44.2( \pm 5.5)$ & $45.2( \pm 5.5)$ & $43.5( \pm 5.5)$ & 0.330 \\
BMI $z$ score & $3.5( \pm 0.3)$ & $3.6( \pm 0.3)$ & $3.5( \pm 0.3)$ & 0.420 \\
Neck circumference $(\mathrm{cm})$ & $40.9( \pm 3.5)$ & $41.4( \pm 3.2)$ & $40.6( \pm 3.7)$ & 0.423 \\
Abdominal circumference $(\mathrm{cm})$ & $126.5( \pm 13.7)$ & $127.8( \pm 15.6)$ & $125.6( \pm 12.4)$ & 0.625 \\
Hip circumference $(\mathrm{cm})$ & $131.7( \pm 10.3)$ & $132.5( \pm 9.2)$ & $131.2( \pm 11.2)$ & 0.674 \\
Waist-length ratio & $0.7( \pm 0.2)$ & $0.7( \pm 0.3)$ & $0.7( \pm 0.1)$ & 0.466 \\
Waist-hip ratio & $1.0( \pm 0.9)$ & $1.0( \pm 0.1)$ & $1.0( \pm 0.1)$ & 0.835 \\
Fat free mass $(\%)$ & $66.2( \pm 11.1)$ & $69.6( \pm 15.0)$ & $66.1( \pm 7.6)$ & 0.336 \\
\hline
\end{tabular}

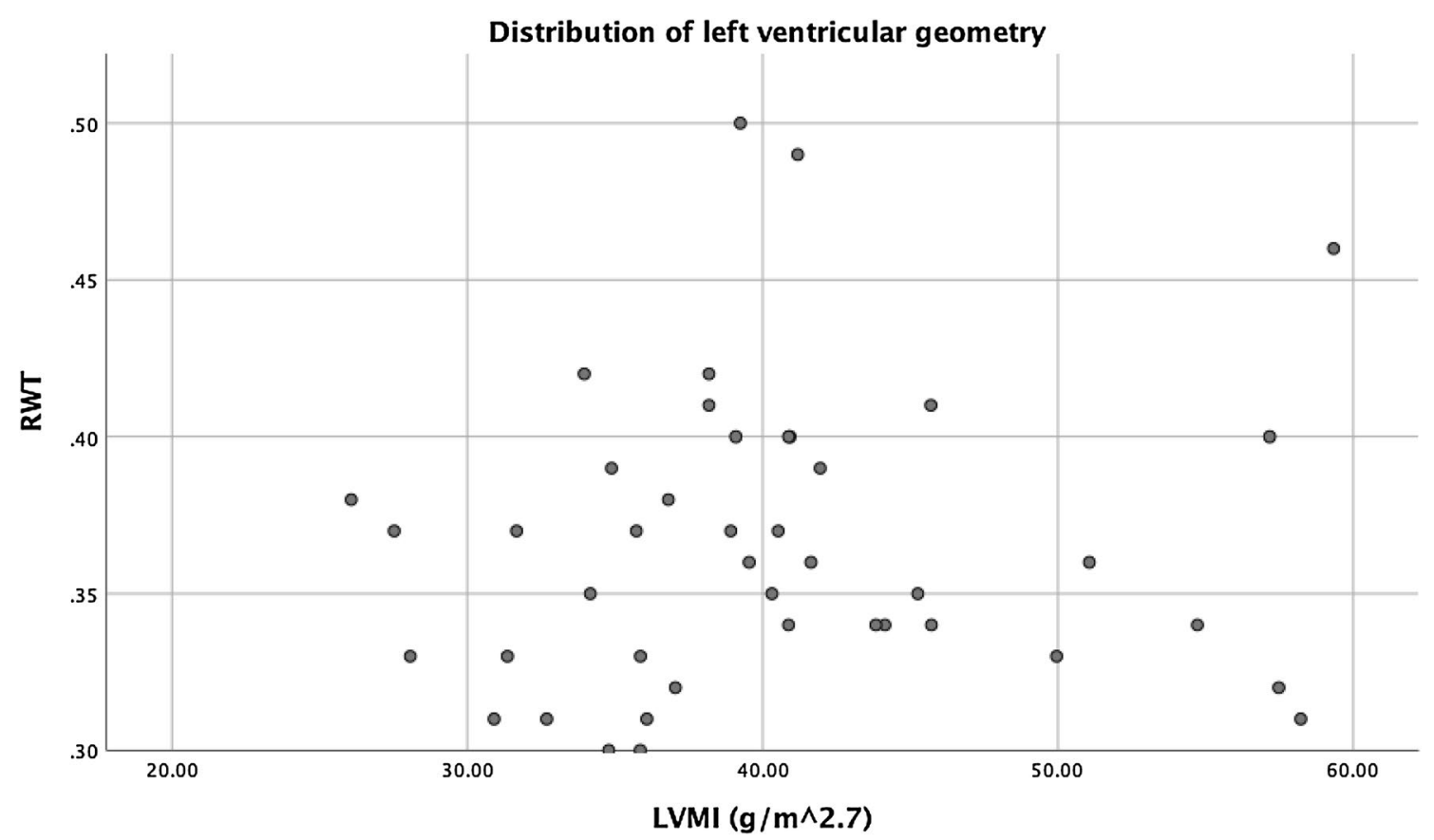

Fig. 1 Distribution of left ventricular geometry in morbidly obese adolescents. $R W T$ relative wall thickness, $L V M I$ left ventricular mass index. A LVMI of $>38.6 \mathrm{~g} / \mathrm{m}^{2.7}$ was considered as hypertrophy. A

observe any statistically significant differences in these factors between patients with LVH and patients without LVH. As a sensitivity analysis, we further analyzed our data using the adult cut-off for LVH $\left(\geq 51.0 \mathrm{~g} / \mathrm{m}^{2.7}\right)$, upon which only six patients $(14.0 \%)$ would have LVH with no statistically significant differences between the group with LVH and without LVH.

By contrast, multivariable linear regression analysis, correcting for BMI $z$ score, showed that increased LVMI was associated with higher AHI (see Table 3). In our study population, 38 patients received polysomnographic evaluation $(88.4 \%)$. The mean AHI was $5.8( \pm 5.2)$, ranging
RWT $>0.41$ was regarded as concentric LVH or concentric remodeling, depending on the LVMI. A RWT $\leq 0.41$ was regarded as eccentric LVH or normal geometry, depending on the LVMI

from 0 to 20.1. For purpose of this analysis, we square-root transformed AHI, which had a right-skewed distribution, to sqrtAHI, upon which normal distribution was achieved. We found that higher LVMI was associated with higher AHI (regression coefficient $B=0.8 ; 95 \%$ CI 0.3 to 1.2 ) as well as sqrtAHI $(B=3.6 ; 95 \%$ CI 1.3 to 5.9$)$ after correction for BMI $z$ score. The association of AHI and sqrtAHI with LVMI persisted after further correcting for age and sex in addition to BMI $z$ score $(B=0.8 ; 95 \%$ CI 0.3 to 1.3 , and $B=3.7 ; 95 \%$ CI 1.3 to 6.1 ).

Furthermore, we found that higher IVST was associated with a number of cosevere risk factors, namely higher fasting 
Table 2 Potentially pathogenic characteristics for overall population and patients with LVH

\begin{tabular}{lllll}
\hline Variable & Overall $(n=43)$ & No LVH $(n=19)$ & LVH $(n=24)$ & $p$-value \\
\hline Blood pressure related & & & & \\
SBP $(\mathrm{mmHg})$ & $121.4( \pm 11.3)$ & $118.7( \pm 11.4)$ & $123.3( \pm 11.0)$ & 0.221 \\
DBP $(\mathrm{mmHg})$ & $69.5( \pm 9.1)$ & $68.0( \pm 9.5)$ & $70.5( \pm 9.0)$ & 0.417 \\
$z$ score SBP & $0.7( \pm 1.0)$ & $0.4( \pm 1.1)$ & $0.9( \pm 1.0)$ & 0.134 \\
$z$ score DBP & $0.3( \pm 0.8)$ & $0.2( \pm 0.9)$ & $0.4( \pm 0.7)$ & 0.485 \\
Glycemic control & & & & \\
Fasting glucose $(\mathrm{mmol} / \mathrm{l})$ & $5.4( \pm 1.8)$ & $5.6( \pm 2.7)$ & $5.2( \pm 0.5)$ & 0.451 \\
Fasting insulin $(\mathrm{pmol} / \mathrm{l})$ & $208.1( \pm 126.0)$ & $210.6( \pm 144.0)$ & $207.2( \pm 113.8)$ & 0.933 \\
HbA1c $(\%)$ & $5.5( \pm 1.3)$ & $5.6( \pm 2.0)$ & $5.4( \pm 0.3)$ & 0.663 \\
HOMA-IR & $7.3( \pm 4.9$ & $7.6( \pm 5.5)$ & $7.1( \pm 4.5)$ & 0.705 \\
Lipid profile & & & & \\
TC (mmol/l) & $4.7( \pm 0.9)$ & $4.7( \pm 0.9)$ & $4.6( \pm 0.9)$ & 0.705 \\
HDL-c $(\mathrm{mmol} / \mathrm{l})$ & $1.1( \pm 0.4)$ & $1.1( \pm 0.5)$ & $1.1( \pm 0.3)$ & 0.477 \\
Ratio TC/HDL-c & $4.7( \pm 1.7)$ & $4.7( \pm 2.1)$ & $4.6( \pm 1.4)$ & 0.801 \\
LDL-c (mmol/l) & $2.7(+0.9)$ & $2.8( \pm 1.0)$ & $2.7( \pm 0.8)$ & 0.590 \\
FFA (mmol/l) & $0.8( \pm 0.3)$ & $0.8( \pm 0.3)$ & $0.9( \pm 0.2)$ & 0.599 \\
Triglycerides $(\mathrm{mmol} / \mathrm{l})$ & $1.9( \pm 0.9)$ & $1.8( \pm 1.0)$ & $1.9( \pm 0.8)$ & 0.855 \\
OSA-related variables & & & & \\
AHI & $5.8( \pm 5.2)$ & $4.3( \pm 3.6)$ & $7.0( \pm 6.1)$ & 0.119 \\
Average O ${ }_{2}$-dip $(\%)$ & $3.0( \pm 0.5)$ & $3.0(0.7)$ & $2.9(0.3)$ & 0.385 \\
\hline
\end{tabular}

insulin ( $B=0.005 ; 95 \%$ CI 0.002 to 0.007$)$, higher HOMAIR $(B=0.1 ; 95 \%$ CI 0.04 to 0.2$)$, lower HDL-c $(B=-1.2$; $95 \% \mathrm{CI}-2.2$ to 0.1$)$, higher triglyceride levels $(B=0.5 ; 95 \%$ CI 0.001 to 0.9$)$, and higher AHI ( $B=0.1 ; 95 \%$ CI 0.01 to 0.2 ), independent of BMI z score. After further correcting for age and gender, significance persisted for AHI, HOMAIR, and fasting insulin levels.

\section{Discussion}

The major findings from our study population of severely obese adolescents are as follows: (1) LVH is highly prevalent and is mostly of the eccentric type; (2) higher LVMI is not significantly associated with anthropometric measures but is independently associated with male gender and higher AHI, the latter implying a pathophysiological relationship between nocturnal hypoxemia and LVH; (3) higher IVST is associated with male gender, lower insulin sensitivity, adverse lipid profile, and higher AHI, independent of BMI z score, which suggests that IVST is associated with an adverse metabolic profile in severely obese adolescents.

Multiple studies describing geometrical changes in obese children have been performed, though they are limited by a high level of intra- and interstudy variability in population characteristics (e.g., a wide range of age, BMI, and ethnicity) and methodology (e.g., different definitions of geometrical aberration), resulting in a reported prevalence of LVH ranging from 10 to $46 \%$ [1-6]. Additionally, some studies report that the most common change is eLVH [1, 2], while others report a higher prevalence of cLVR [3] or cLVH [4]. Moreover, data regarding severely obese adolescent patients is scarce, and recent literature is limited to a single study by Ippisch et al. [4]. In our study population of 43 severely obese adolescents aged 14-16 years old (average $15.7 \pm 1.0$ years), we found that $60.5 \%$ suffered from abnormal left ventricular geometry overall, with eLVH in $48.8 \%$ and cLVH in $4.6 \%$. Ippisch et al. describe a similar prevalence of abnormal left ventricular geometry of $64 \%$ in their population of 13-19 year old patients with a mean BMI of $60 \pm 9 \mathrm{~kg} / \mathrm{m}^{2}$, though they used the adult cut-off of the LVMI of $51 \mathrm{~g} / \mathrm{m}^{2.7}$ [4]. When applying the same cut-off of LVMI in our population, only six patients (14.0\%) would suffer from LVH, possibly because the population in the study of Ippisch et al. had on average an even higher BMI than our population $\left(15.8 \mathrm{~kg} / \mathrm{m}^{2}\right.$ difference). We recommend that future studies evaluate more specifically defined populations and determine left ventricular geometry by utilization of LVMI $\left(\mathrm{g} / \mathrm{m}^{2.7}\right)$ and RWT, using the pediatric $95^{\text {th }}$ percentile cut-off values of $38.6 \mathrm{~g} / \mathrm{m}^{2.7}$ and $0.41 \mathrm{~cm}$, respectively, or reporting results using both the pediatric and adult cut-off values [24, 25, 27].

The association between anthropometric measures, in particular BMI and abdominal circumference, with metabolic syndrome is well established [28]. Similarly, several anthropometric variables, including BMI, waist circumference, waist-hip ratio, and waist-length ratios are associated with LVM in adults [29-34]. The pediatric literature relating 
Table 3 Unstandardized regression coefficients B and 95\% confidence intervals, indicating associations of various variables with left ventricular geometrical indices, corrected for BMI $z$ score. Statistically significant differences emphasized with a bold font

\begin{tabular}{|c|c|c|c|c|c|}
\hline & LVMI $\left(\mathrm{g} / \mathrm{m}^{2.7}\right)$ & $\operatorname{LVM}(\mathrm{g})$ & IVST (mm) & LPWT (mm) & LVEDD (mm) \\
\hline \multicolumn{6}{|l|}{ Demographic variables } \\
\hline Age (years) & $0.6(-2.2$ to 3.4$)$ & $4.6(-9.4$ to 18.6$)$ & $0.06(-0.3$ to 0.5$)$ & $-0.1(-0.5$ to 0.2$)$ & $0.9(-0.6$ to 2.5$)$ \\
\hline Gender female & $-4.3(-11.0$ to 2.4$)$ & $\begin{array}{l}-68.1(-95.3 \text { to } \\
40.9)\end{array}$ & $-1.9(-2.7$ to 1.1$)$ & $-0.4(-1.2$ to 0.4$)$ & $-6.6(-9.8$ to 3.3$)$ \\
\hline \multicolumn{6}{|c|}{ Anthropometric variables } \\
\hline BMI $\left(\mathrm{kg} / \mathrm{m}^{2}\right)^{*}$ & $-0.1(-0.6$ to 0.3$)$ & $-0.8(-3.3$ to 1.6$)$ & $\begin{array}{l}-0.006 \text { ( }-0.08 \text { to } \\
0.07)\end{array}$ & $\begin{array}{l}-0.004(-0.06 \text { to } \\
0.05)\end{array}$ & $-0.1(-0.4$ to 0.1$)$ \\
\hline BMI $z$ score* & $-1.5(-9.9$ to 6.9$)$ & $5.7(-37.3$ to 48.7$)$ & $0.2(-1.0$ to 1.5$)$ & $-0.2(-0.8$ to 1.2$)$ & $-0.3(-5.2$ to 4.5$)$ \\
\hline $\begin{array}{l}\text { Neck circumference } \\
(\mathrm{cm})\end{array}$ & $-0.5(-1.5$ to 0.5$)$ & $3.2(-1.7$ to 8.1$)$ & $0.1(-0.006$ to 0.3$)$ & $-0.02(-0.1$ to 0.1$)$ & $0.2(-0.4$ to 0.7$)$ \\
\hline $\begin{array}{l}\text { Abdominal circum- } \\
\text { ference }(\mathrm{cm})\end{array}$ & $0.01(-0.3$ to 0.3$)$ & $1.0(-0.5$ to 2.5$)$ & $0.03(-0.02$ to 0.07$)$ & $\begin{array}{l}-0.002(-0.04 \text { to } \\
0.03)\end{array}$ & $0.1(-0.03$ to 0.3$)$ \\
\hline $\begin{array}{l}\text { Hip circumference } \\
(\mathrm{cm})\end{array}$ & $-0.1(-0.6$ to 0.3$)$ & $-0.9(-3.0$ to 1.1$)$ & $\begin{array}{l}-0.006(-0.07 \text { to } \\
0.06)\end{array}$ & $0.01(-0.04$ to 0.06$)$ & $-0.2(-0.4$ to 0.07$)$ \\
\hline Waist-length ratio & $4.1(-9.0$ to 17.2$)$ & $-5.7(-73.0$ to 61.6$)$ & $0.2(-1.8$ to 2.1$)$ & $-0.6(-1.0$ to 2.1$)$ & $-2.6(-10.1$ to 4.8$)$ \\
\hline Waist-hip ratio & $9.741(-23.2$ to 42.7$)$ & $\begin{array}{l}144.2(-18.4 \text { to } \\
306.9)\end{array}$ & $3.2(-1.6$ to 8.1$)$ & $-0.8(-4.7$ to 3.2$)$ & 21.5 (3.9 to 39.1) \\
\hline Fat free mass $(\%)$ & $-0.2(-0.4$ to 0.1$)$ & $-0.6(-1.8$ to 0.7$)$ & $-0.01(-0.05$ to 0.02$)$ & $\begin{array}{l}-0.005(-0.04 \text { to } \\
0.02)\end{array}$ & -0.07 ( -0.2 to 0.07$)$ \\
\hline \multicolumn{6}{|l|}{ Blood pressure related } \\
\hline $\mathrm{SBP}(\mathrm{mmHg})$ & $0.2(-0.1$ to 0.4$)$ & $0.9(-0.3$ to 2.2$)$ & $0.03(-0.006$ to 0.07$)$ & $0.02(-0.01$ to 0.04$)$ & $0.07(-0.8$ to 0.2$)$ \\
\hline $\mathrm{DBP}(\mathrm{mmHg})$ & $0.1(-0.2$ to 0.4$)$ & $0.6(-0.9$ to 2.1$)$ & $0.03(-0.02$ to 0.08$)$ & $0.02(-0.02$ to 0.05$)$ & $-0.002(-0.2$ to 0.2$)$ \\
\hline$z$ score SBP & $1.7(-0.8$ to 4.2$)$ & $0.1(-13.2$ to 13.4$)$ & $0.1(-0.3$ to 0.5$)$ & $0.1(-0.2$ to 0.4$)$ & $-0.3(-1.8$ to 1.1$)$ \\
\hline$z$ score DBP & $1.9(-1.5$ to 5.2$)$ & $0.2(-17.0$ to 17.4$)$ & $0.2(-0.3$ to 0.7$)$ & $0.2(-0.2$ to 0.6$)$ & $-0.8(-2.7$ to 1.1$)$ \\
\hline \multicolumn{6}{|l|}{ Glycemic control } \\
\hline $\begin{array}{l}\text { Fasting glucose } \\
(\mathrm{mmol} / \mathrm{l})\end{array}$ & $-1.2(-2.6$ to 0.2$)$ & $-3.1(-10.4$ to 4.3$)$ & $-0.01(-0.2$ to 0.2$)$ & $-0.05(-0.2$ to 0.1$)$ & $-0.5(-1.3$ to 0.3$)$ \\
\hline $\begin{array}{l}\text { Fasting insulin } \\
(\mathrm{pmol} / \mathrm{l})\end{array}$ & $\begin{array}{l}-0.001(-0.02 \text { to } \\
0.02)\end{array}$ & $0.04(-0.07$ to 0.2$)$ & $0.005(0.002$ to 0.007$)$ & $\begin{array}{l}0.001(-0.002 \text { to } \\
0.003)\end{array}$ & $\begin{array}{l}-0.002(-0.02 \text { to } \\
0.01)\end{array}$ \\
\hline HbA1c (\%) & $-1.7(-3.6$ to 0.3$)$ & $-5.5(-15.6$ to 4.6$)$ & $-0.03(-0.3$ to 0.3$)$ & $-0.08(-0.3$ to 0.2$)$ & $-0.8(-1.9$ to 0.3$)$ \\
\hline HOMA-IR & $-0.2(-0.8$ to 0.4$)$ & $0.6(-2.3$ to 3.6$)$ & $0.1(0.04$ to 0.2$)$ & $0.005(-0.06$ to 0.07$)$ & $-0.1(-0.5$ to 0.2$)$ \\
\hline \multicolumn{6}{|l|}{ Lipid profile } \\
\hline $\mathrm{TC}(\mathrm{mmol} / \mathrm{l})$ & $-1.6(-4.6$ to 1.3$)$ & $-6.0(-21.2$ to 9.1$)$ & $0.01(-0.4$ to 0.5$)$ & $-0.05(-0.4$ to 0.3$)$ & $-1.2(-2.8$ to 0.5$)$ \\
\hline HDL-c (mmol/l) & $-4.8(-12.3$ to 2.6$)$ & $-32.8(-70.3$ to 4.7$)$ & $-1.2(-2.2$ to 0.1$)$ & $-0.7(-1.5$ to 0.2$)$ & $-1.6(-5.9$ to 2.7$)$ \\
\hline Ratio TC/HDL-c & $0.1(-1.5$ to 1.7$)$ & $2.4(-5.6$ to 10.4$)$ & $0.2(-0.07$ to 0.4$)$ & $0.05(-0.1$ to 0.2$)$ & $-0.1(-1.0$ to 0.8$)$ \\
\hline LDL-c (mmol/l) & $-1.6(-4.6$ to 1.4$)$ & $-6.1(-21.6$ to 9.3$)$ & $-0.04(-0.5$ to 0.4$)$ & $-0.04(-0.4$ to 0.3$)$ & $-1.1(-2.8$ to 0.6$)$ \\
\hline FFA (mmol/l) & $-3.5(-13.7$ to 6.7$)$ & $-32.9(-85.0$ to 19.2$)$ & $-0.2(-1.8$ to 1.4$)$ & $-0.2(-1.5$ to 1.0$)$ & $-5.7(-11.2$ to 0.2$)$ \\
\hline $\begin{array}{l}\text { Triglycerides } \\
(\mathrm{mmol} / \mathrm{l})\end{array}$ & $-0.3(-3.5$ to 2.8$)$ & $7.2(-8.8$ to 23.1$)$ & $0.5(0.008$ to 0.9$)$ & $0.1(-0.3$ to 0.5$)$ & $-0.2(-2.0$ to 1.6$)$ \\
\hline \multicolumn{6}{|l|}{ OSA-related variables } \\
\hline AHI & $0.8(0.3$ to 1.2$)$ & $2.5(-0.03$ to 5.1$)$ & $0.1(0.01$ to 0.2$)$ & $0.1(0.02$ to 0.1$)$ & $0.06(-0.3$ to 0.4$)$ \\
\hline sqrtAHI & $3.6(1.3$ to 5.9$)$ & 13.2 (1.1 to 25.2$)$ & $0.5(0.1$ to 0.8$)$ & $0.4(0.08$ to 0.6$)$ & $0.4(-1.09$ to 2.0$)$ \\
\hline Average $\mathrm{O}_{2}$-dip (\%) & $-1.9(-7.2$ to 3.5$)$ & $-18.0(-44.0$ to 8.0$)$ & $-0.2(-1.0$ to 0.6$)$ & $-0.3(-0.9$ to 0.3$)$ & $-2.3(-5.4$ to 0.8$)$ \\
\hline
\end{tabular}

*not corrected

anthropometric measures with LVM is limited [5]. Daniels et al. described a significant association between LVM and body fat percentage [5]. Within our homogeneous study population of severely obese adolescents with a BMI of $44.2 \mathrm{~kg} / \mathrm{m}^{2}( \pm 5.5)$, we did not find an association between
LVH and any anthropometric variable, such as BMI, neck circumference, and abdominal circumference. Our findings by them self could suggest that in this population at high risk for LVH, additional anthropometric measurements are not valuable to stratify risk. However, the findings by Ippisch 
et al. raise the question whether further increases in BMI are associated with an increased severity of left ventricular hypertrophy [4].

Our hypothesis that higher LVM could be independently associated with an adverse metabolic profile was based on the adult literature that shows an independent association between higher LVM, insulin resistance, and dyslipidemia [35-39]. We did not find any such association with LVM or LVMI. By contrast, we found that IVST is associated with several variables related to comorbidity, namely HOMAIR, HDL-c, triglyceride levels, and AHI, independent of BMI z score. After further correction for age and gender, associations remain significant for insulin levels, HOMAIR, and AHI. Previously, multiple studies established that increased IVST is associated with an adverse metabolic profile [40-42], higher blood pressure in young healthy adults $[43,44]$, and higher all-cause mortality in adults with cardiovascular disease $[45,46]$. Our findings support the hypothesis that hyperinsulinemia plays a role in the nonhemodynamic pathogenesis of cardiac hypertrophy, albeit limited to the ventricular septum. Multiple pathogenic mechanisms by which insulin resistance contributes to altered left ventricular geometry are proposed in the literature, including increased fatty acid oxidation with accumulation of cardiotoxic metabolic intermediates and direct binding of insulin to insulin-like growth factor 1 receptors, resulting in cardiomyocyte proliferation [47-51].

We did not find an association between blood pressure and any parameter of left ventricular geometry (LVMI, LVM, IVST, LPWT, or LVEDD), possibly because the levels of systolic and diastolic blood pressure in our population were relatively normal, with $\mathrm{z}$ scores of $0.7( \pm 1.0)$ and 0.3 $( \pm 0.8)$, respectively. These findings are in conjunction with the observations of the Bogalusa heart study, which found that increased left ventricular mass in obese children and young adults preceded the development of increases in systolic and diastolic blood pressure [14]. This further emphasizes the importance of considering obesity as an independent modifiable risk factor for cardiac geometrical changes.

OSA is a well-established independent risk factor for LVH in adults, both through hemodynamic and nonhemodynamic mechanisms [52]. Cloward et al. demonstrated that treatment of OSA in adults resulted in a reduction in interventricular septal thickness [53]. Amin et al. found that in children and adolescents, an AHI $>10$ was associated with a significantly higher risk of LVH when compared to primary snorers (odds ratio $11.2,95 \%$ confidence interval 1.9-64) [54]. Chan et al. evaluated children between 6 and 13 years old with or without OSA and found that higher AHI values were associated with increased IVST and RWT [55]. Furthermore, they found that improvement of OSA resulted in improvement of these variables [55]. Recently, Hanlon et al. compared the prevalence of LVH in 61 subjects with or without OSA, with a mean age of 13.1 years and a median BMI of $36.3 \mathrm{~kg} / \mathrm{m}^{2}$ [6]. They found that OSA was an independent risk factor of $\mathrm{LVH}$ and that the risk of LVH increased with the severity of OSA. In our study, we found that squareroot-transformed AHIs were associated with LVMI, LVM, IVST, and LVPWT, independent of BMI z score. Regression coefficients remained significant, also after further correction for age and gender. Importantly, OSA is highly prevalent in severely obese adolescents, with $86.9 \%$ of our patients having an $\mathrm{AHI} \geq 1$ and $39.5 \%$ having an $\mathrm{AHI} \geq 5$, corresponding to mild and moderate-severe OSA, respectively [56]. Our findings support the notion that OSA is an important pathogenic factor in obesity-related LVH and indicate the importance of early recognition and treatment of this serious comorbidity.

The main strengths of our study are a high level of methodological standardization and extensive evaluation across several relevant clinical domains. Our study population consists of well-defined prospectively recruited severely obese adolescents aged 14-16 years, allowing adequate characterization of this specific population. We were able to evaluate multiple hypotheses related to the determinants of LVH in severely obese adolescents, owing to the extensive data we have on the overall condition of our study population, including hemodynamic factors, metabolic aberrations, and polysomnographic characteristics.

Our study has a number of limitations. A significant number of patients did not receive cardiac ultrasound due to logistic reasons, resulting in a limited sample size. This may have hampered the statistical significance of certain findings and did not allow us to investigate all risk factors in one model, i.e., correcting for the influence of these factors on each other. Moreover, our population concerns mainly females, and therefore, the applicability of these findings to male severely obese adolescents cannot be guaranteed.

We conclude that LVH, especially eLVH, occurs in the majority of severely obese adolescents and that adverse geometrical changes, in particular increased IVST, are independently associated with multiple commonly occurring nonhemodynamic risk factors, including OSA, dyslipidemia, and insulin resistance. We recommend low threshold of suspicion of these risk factors and proactive treatment, in order to potentially improve cardiovascular prognosis. Future research should focus on the effect of reversal of these risk factors on cardiac geometry.

\section{Compliance with Ethical Standards}

Conflict of interest None of the authors have a disclosure to declare. 
Open Access This article is licensed under a Creative Commons Attribution 4.0 International License, which permits use, sharing, adaptation, distribution and reproduction in any medium or format, as long as you give appropriate credit to the original author(s) and the source, provide a link to the Creative Commons licence, and indicate if changes were made. The images or other third party material in this article are included in the article's Creative Commons licence, unless indicated otherwise in a credit line to the material. If material is not included in the article's Creative Commons licence and your intended use is not permitted by statutory regulation or exceeds the permitted use, you will need to obtain permission directly from the copyright holder. To view a copy of this licence, visit http://creativecommons.org/licenses/by/4.0/.

\section{References}

1. Di Bonito P, Sanguigno E, Forziato C, Di Fraia T, Moio N, Cavuto L, Sibilio G, Iardino MR, Di Carluccio C, Capaldo B (2014) Glomerular filtration rate and cardiometabolic risk in an outpatient pediatric population with high prevalence of obesity: glomerular filtration rate in children. Obesity 22(2):585-589

2. Khositseth A, Suthutvoravut U, Chongviriyaphan N (2009) Left ventricular mass and geometry in obese children. Asian J Clin Nutr 1(1):58-64

3. Dhuper S, Abdullah RA, Weichbrod L, Mahdi E, Cohen HW (2011) Association of obesity and hypertension with left ventricular geometry and function in children and adolescents. Obesity 19(1):128-133

4. Ippisch HM, Inge TH, Daniels SR, Wang B, Khoury PR, Witt SA, Glascock BJ, Garcia VF, Kimball TR (2008) Reversibility of cardiac abnormalities in morbidly obese adolescents. J Am Coll Cardiol 51(14):1342-1348

5. Daniels SR, Morrison JA, Sprecher DL, Khoury P, Kimball TR (1999) Association of body fat distribution and cardiovascular risk factors in children and adolescents. Circulation 99(4):541-545

6. Hanlon CE, Binka E, Garofano JS, Sterni LM, Brady TM (2019) The association of obstructive sleep apnea and left ventricular hypertrophy in obese and overweight children with history of elevated blood pressure. J Clin Hypertens 21(7):984-990

7. de Simone G, Devereux RB, Daniels SR, Koren MJ, Meyer RA, Laragh JH (1995) Effect of growth on variability of left ventricular mass: assessment of allometric signals in adults and children and their capacity to predict cardiovascular risk. J Am Coll Cardiol 25(5):1056-1062

8. Koren MJ (1991) Relation of left ventricular mass and geometry to morbidity and mortality in uncomplicated essential hypertension. Ann Intern Med 114(5):345

9. Chen X, Wang Y (2008) Tracking of blood pressure from childhood to adulthood: a systematic review and meta-regression analysis. Circulation 117(25):3171-3180

10. Morrison JA, Friedman LA, Gray-McGuire C (2007) Metabolic syndrome in childhood predicts adult cardiovascular disease 25 years later: the princeton lipid research clinics follow-up study. Pediatrics 120(2):340-345

11. Verdecchia P, Schillaci G, Borgioni C, Ciucci A, Gattobigio R, Zampi I, Reboldi G, Porcellati C (1998) Prognostic significance of serial changes in left ventricular mass in essential hypertension. Circulation 97(1):48-54

12. Karason K, Wallentin I, Larsson B, Sjöström L (1997) Effects of obesity and weight loss on left ventricular mass and relative wall thickness: survey and intervention study. BMJ 315(7113):912-916
13. Brady TM, Fivush B, Flynn JT, Parekh R (2008) Ability of blood pressure to predict left ventricular hypertrophy in children with primary hypertension. J Pediatr 152(1):73-78.e1

14. Urbina EM, Gidding SS, Bao W, Pickoff AS, Berdusis K, Berenson GS (1995) Effect of body size, ponderosity, and blood pressure on left ventricular growth in children and young adults in the bogalusa heart study. Circulation 91(9):2400-2406

15. Crowley DI, Khoury PR, Urbina EM, Ippisch HM, Kimball TR (2011) Cardiovascular impact of the pediatric obesity epidemic: higher left ventricular mass is related to higher body mass index. J Pediatr 158(5):709-714.e1

16. Brady TM (2016) The role of obesity in the development of left ventricular hypertrophy among children and adolescents. Curr Hypertens Rep 18(1):3

17. Toprak A, Wang H, Chen W, Paul T, Srinivasan S, Berenson G (2008) Relation of childhood risk factors to left ventricular hypertrophy (eccentric or concentric) in relatively young adulthood (from the Bogalusa Heart Study). Am J Cardiol 101(11):1621-1625

18. Roebroek YGM, Paulus GF, van Mil EGAH, Vreugdenhil ACE, Winkens B, Nederkoorn C, Stehouwer CDA, Greve JWM, Bouvy ND, van Heurn LWE (2019) Bariatric surgery in adolescents: a prospective randomized controlled trial comparing laparoscopic gastric banding to combined lifestyle interventions in adolescents with severe obesity (BASIC trial). BMC Pediatr 19(1):34

19. Cole TJ, Lobstein T (2012) Extended international (IOTF) body mass index cut-offs for thinness, overweight and obesity. Pediatr Obes 7(4):284-294

20. National High Blood Pressure Education Program Working Group on High Blood Pressure in Children and Adolescents (2004) The fourth report on the diagnosis, evaluation, and treatment of high blood pressure in children and adolescents. Pediatrics 114(24):555-576

21. Matthews DR, Hosker JP, Rudenski AS, Naylor BA, Treacher DF, Turner RC (1985) Homeostasis model assessment: insulin resistance and ?-cell function from fasting plasma glucose and insulin concentrations in man. Diabetologia 28(7):412-419

22. Berry RB, Budhiraja R, Gottlieb DJ, Gozal D, Iber C, Kapur VK, Marcus CL, Mehra R, Parthasarathy S, Quan SF, Redline S, Strohl KP, Davidson Ward SL, Tangredi MM (2012) Rules for scoring respiratory events in sleep: update of the 2007 AASM Manual for the Scoring of Sleep and Associated Events. Deliberations of the sleep apnea definitions task force of the American Academy of Sleep Medicine. J Clin Sleep Med JCSM 8(5):597-619

23. Devereux RB, Alonso DR, Lutas EM, Gottlieb GJ, Campo E, Sachs I, Reichek N (1986) Echocardiographic assessment of left ventricular hypertrophy: comparison to necropsy findings. Am J Cardiol 57(6):450-458

24. de Simone G, Devereux RB, Roman MJ, Alderman MH, Laragh JH (1994) Relation of obesity and gender to left ventricular hypertrophy in normotensive and hypertensive adults. Hypertens Dallas Tex 1979 23(5):600-606

25. Daniels SR, Kimball TR, Morrison JA, Khoury P, Witt S, Meyer RA (1995) Effect of lean body mass, fat mass, blood pressure, and sexual maturation on left ventricular mass in children and adolescents: statistical, biological, and clinical significance. Circulation 92(11):3249-3254

26. Ganau A, Devereux RB, Roman MJ, de Simone G, Pickering TG, Saba PS, Vargiu P, Simongini I, Laragh JH (1992) Patterns of left ventricular hypertrophy and geometric remodeling in essential hypertension. J Am Coll Cardiol 19(7):1550-1558

27. Daniels SR, Meyer RA, Liang Y, Bove KE (1988) Echocardiographically determined left ventricular mass index in normal children, adolescents and young adults. J Am Coll Cardiol 12(3):703-708 
28. Eckel RH, Grundy SM, Zimmet PZ (2005) The metabolic syndrome. Lancet 365(9468):1415-1428

29. Gupta RK, Gupta R, Makar N, Chaudhary S, Bhatheja H, Pathak $\mathrm{P}$ (2016) The association of left ventricular mass index with metabolic syndrome in comparison to hypertensive patients. J Cardiovasc Echogr 26(2):42-47

30. Ponce S, Allison MA, Swett K, Cai J, Desai AA, Hurwitz BE, Ni A, Schneiderman N, Shah SJ, Spevack DM, Talavera GA, Rodriguez CJ (2018) The associations between anthropometric measurements and left ventricular structure and function: the Echo-SOL Study. Obes Sci Pract 4(4):387-395

31. Rodrigues SL, Baldo MP, Sá Cunha R, Angelo LC, Pereira AC, Krieger JE, Mill JG (2010) Anthropometric measures of increased central and overall adiposity in association with echocardiographic left ventricular hypertrophy. Hypertens Res 33(1):83-87

32. Stel VS, Ioannou K, Bruck K, Dounousi E, Pappas K, Siamopoulos KC, Zoccali C, Jager KJ, Tsakiris D (2013) Longitudinal association of body mass index and waist circumference with left ventricular mass in hypertensive predialysis chronic kidney disease patients. Nephrol Dial Transplant. 28(suppl 4):136-145

33. Chumlea WMC, Schubert CM, Towne B, Siervogel RM, Sun SS (2009) Left ventricular mass, abdominal circumference and age: the Fels Longitudinal Study. J Nutr Health Aging. 13(9):821-825

34. Bombelli M, Facchetti R, Sega R, Carugo S, Fodri D, Brambilla G, Giannattasio C, Grassi G, Mancia G (2011) Impact of body mass index and waist circumference on the long-term risk of diabetes mellitus, hypertension, and cardiac organ damage. Hypertension 58(6):1029-1035

35. Bulut C, Helvaci A, Adas M, Ozsoy N, Bayyigit A (2016) The relationship between left ventricular mass and insulin resistance in obese patients. Indian Heart J 68(4):507-512

36. Nkum BC, Micah FB, Ankrah TC, Nyan O (2014) Left ventricular hypertrophy and insulin resistance in adults from an urban community in The Gambia: cross-sectional study. PLoS ONE 9(4):e93606

37. Cardona-Muñoz EG, Cardona-Müller D, Totsuka-Sutto S, NuñoGuzmán CM, Pascoe-González S, Romero-Prado M, MirandaDíaz AG (2007) Association of hyperinsulinemia with left ventricular hypertrophy and diastolic dysfunction in patients with hypertension. Rev Med Chil 135(9):1125-1131

38. Shereef A, Kandeel N (2019) The relation between insulin resistance and left ventricular mass in hypertensive nondiabetic patients. J INDIAN Coll Cardiol 9(2):100

39. Kuch B, von Scheidt W, Peter W, Doring A, Piehlmeier W, Landgraf R, Meisinger C (2007) Sex-specific determinants of left ventricular mass in pre-diabetic and type 2 diabetic subjects: the augsburg diabetes family study. Diabetes Care 30(4):946-952

40. Burchfiel CM, Skelton TN, Andrew ME, Garrison RJ, Arnett DK, Jones DW, Taylor HA (2005) Metabolic syndrome and echocardiographic left ventricular mass in blacks: the Atherosclerosis Risk in Communities (ARIC) Study. Circulation 112(6):819-827

41. Wang S, Song K, Guo X, Xue H, Wang N, Chen J, Zou Y, Sun K, Wang H, He J, Hui R (2015) The association of metabolic syndrome with left ventricular mass and geometry in communitybased hypertensive patients among Han Chinese. J Res Med Sci 20(10):963-968

42. Straznicky NE, Grima MT, Sari CI, Karapanagiotidis S, Wong C, Eikelis N, Richards KL, Lee G, Nestel PJ, Dixon JB, Lambert GW, Schlaich MP, Lambert EA (2013) The relation of glucose metabolism to left ventricular mass and function and sympathetic nervous system activity in obese subjects with metabolic syndrome. J Clin Endocrinol Metab 98(2):E227-E237

43. Grossman C, Grossman A, Koren-Morag N, Azaria B, Goldstein L, Grossman E (2008) Interventricular septum thickness predicts future systolic hypertension in young healthy pilots. Hypertens Res 31(1):15-20

44. Eliakim-Raz N, Prokupetz A, Gordon B, Shochat T, Grossman A (2016) Interventricular septum and posterior wall thickness are associated with higher systolic blood pressure. J Clin Hypertens 18(7):703-706

45. Huang B-T, Peng Y, Liu W, Zhang C, Huang F-Y, Wang P-J, Zuo Z-L, Liao Y-B, Chai H, Huang K-S, Huang D-J, Chen M (2015) Increased interventricular septum wall thickness predicts all-cause death in patients with coronary artery disease: Thickened IVS and mortality in CAD. Intern Med J 45(3):275-283

46. Jensen MK, Jacobsson L, Almaas V, VanBuuren F, Hansen PR, Hansen TF, Aakhus S, Eriksson MJ, Bundgaard H, Faber L (2016) Influence of septal thickness on the clinical outcome after alcohol septal alation in hypertrophic cardiomyopathy. Circ Cardiovasc Interv. https://doi.org/10.1161/CIRCINTERVENTIO NS.115.003214

47. Wong CY, O'Moore-Sullivan T, Leano R, Byrne N, Beller E, Marwick TH (2004) Alterations of left ventricular myocardial characteristics associated with obesity. Circulation 110(19):3081-3087

48. Peterson LR, Herrero P, Schechtman KB, Racette SB, Waggoner AD, Kisrieva-Ware Z, Dence C, Klein S, Marsala J, Meyer T, Gropler RJ (2004) Effect of obesity and insulin resistance on myocardial substrate metabolism and efficiency in young women. Circulation 109(18):2191-2196

49. Katz LEL, Gralewski KA, Abrams P, Brar PC, Gallagher PR, Lipman TH, Brooks LJ, Koren D (2016) Insulin-like growth factorI and insulin-like growth factor binding protein-1 are related to cardiovascular disease biomarkers in obese adolescents. Pediatr Diab 17(2):77-86

50. Chiu H-C, Kovacs A, Ford DA, Hsu F-F, Garcia R, Herrero P, Saffitz JE, Schaffer JE (2001) A novel mouse model of lipotoxic cardiomyopathy. J Clin Invest 107(7):813-822

51. Cittadini A, Strömer H, Katz SE, Clark R, Moses AC, Morgan JP, Douglas PS (1996) Differential cardiac effects of growth hormone and insulin-like growth factor-1 in the rat. A combined in vivo and in vitro evaluation. Circulation 93(4):800-809

52. Pujante P, Abreu C, Moreno J, Barrero EA, Azcarate P, Campo A, Urrestarazu E, Silva C, Maria JG, Tebar J, Frühbeck G, Salvador J (2013) Obstructive sleep apnea severity is associated with left ventricular mass independent of other cardiovascular risk factors in morbid obesity. J Clin Sleep Med 9:1165-1171

53. Cloward TV, Walker JM, Farney RJ, Anderson JL (2003) Left ventricular hypertrophy is a common echocardiographic abnormality in severe obstructive sleep apnea and reverses with nasal continuous positive airway pressure*. Chest 124(2):594-601

54. Amin RS, Kimball TR, Bean JA, Jeffries JL, Willging JP, Cotton RT, Witt SA, Glascock BJ, Daniels SR (2002) Left ventricular hypertrophy and abnormal ventricular geometry in children and adolescents with obstructive sleep apnea. Am J Respir Crit Care Med 165(10):1395-1399

55. Chan JYS, Li AM, Au C-T, Lo AFC, Ng S-K, Abdullah VJ, Ho C, Yu C-M, Fok T-F, Wing Y-K (2009) Cardiac remodelling and dysfunction in children with obstructive sleep apnoea: a community based study. Thorax 64(3):233-239

56. Talib A, Roebroek YGM, van Waardenburg DA, van der Grinten CPM, Winkens B, Bouvy ND, van Heurn ELWE (2020) Obstructive sleep apnea in obese adolescents referred for bariatric surgery: association with metabolic and cardiovascular variables. Sleep Med. https://doi.org/10.1016/j.sleep.2020.02.026

Publisher's Note Springer Nature remains neutral with regard to jurisdictional claims in published maps and institutional affiliations. 